EESTI NSV TEADUSTE AKADEEMIA TOIMETISED. VII KOIDE

BIOLOOGILINE SEERIA. 1958, NR. 1

ИЗВЕСТИЯ АКАДЕМИИ НАУК ЭСТОНСКОЙ ССР. ТОМ VII

СЕРИЯ БИОЛОГИЧЕСКАЯ. 1958, № 1

\title{
VEISTE BABESIELLOOSI KOLLETEST EESTI NSV-S
}

\author{
A. VILBASTE, \\ bioloogiateaduste kandidaat
}

Nõukogude Liidu põhja- ja loodeosas on veiste babesielloosi (punakusesuse) ülekandjana tuntud võsapuuk (Ixodes ricinus). Reas uurimustes märgitakse babesielloosi ülekandmist ka teise NSV Liidu looderajoonides kohati kaunis arvukalt esineva puuliigi - taigapuugi (Ixodes persulcatus) poolt. Seda on kindlaks tehtud nii laboratoorsete katsete (Sudatšenkov, 1941a) kui ka babesielloosijuhtude põhjal, mis on seotud taigapuugi levikualaga (Sudatšenkov, 1941b; Hodakovski, 1939; Tšiž, Konovalov ja Kuntõšev, 1951). Huvitav on märkida, et neis rajoonides, kus esineb $I$. persulcatus, võib babesielloosi kohata vaid üksikjuhtudena või üldse mitte. Lutta ja Heisin (1954) märgivad Karjala ANSV Iõunarajoonides I. persulcatus'e ebaolulist osa babesielloosi edasikandmisel, kuid ei eita selle võimalikkust.

Veiste babesielloosi tekitajaks on ainurakne vereparasiit Babesiella bovis. Puuk, kellele vere imemine on igas arenemisstaadiumis obligatoorne, nakatub haigel veisel toitudes vereparasiitidega ja annab järgmisel imemisel need edasi tervetele veistele. Nagu uurimused on näidanud (Petrov, 1938, 1941; Lotarev, Poljanski ja Heisin, 1957), nakatuvad vereparasiitidega kõik puugi koed, ka munasarjad ja neis arenevad munad. Asjaolud, et puugi munadest kooruvad larvid on juba parasiitide kandjad ja et haiguse tekitaja ise püsib peale babesielloosi põdemist veiste veres pikemat aega (Petraševskaja ja Tšiž, 1939; Fainštein, 1939), aitavad omalt poolt kaasa haigusekollete püsimisele teatud paikades. Kuna on tegemist haigusega, mille tekitaja parasiit (Babesiella bovis) kantakse üle teise parasiidi (puugi) poolt, siis määrab haiguse püsimise terve omavaheliste suhete süsteem, millest iseloomustatakse alljärgnevalt vaid haiguse ülekandjaid (s. t. puuke), nende peremehi, viimaste arvukust ja puukide paljunemistingimusi erinevates Eesti NSV osades.

Euroopa faunas teadaolevatest puugiliikidest on Eesti NSV-s kindlaks tehtud neli: I. ricinus (L.), I. persulcatus P. Sch., I. (Exopalpiger) trianguliceps Bir. ja Haemaphysalis punctata Can. et Franz. (Vilbaste, 1953). Babesielloosi ülekandjatena tuleksid arvesse vaid arvukamalt esinevad I. ricinus ja $I$. persulcatus, kes täiskasvanustaadiumis toituvad suurimetajatel, seal hulgas ka kariloomadel.

I. ricinus't on leitud peaaegu kogu Eesti NSV-s, välja arvatud väiksemad puugivabad «saared» ja vähesed, üksnes $I$. persulcatus'ega asustatud piiratud territooriumiga alad Ida-Eestis (joon. 1).

Olemasolevate andmete põhjal esineb $I$. persulcatus ainult Eesti NSV territooriumi idapoolsel kolmandikul. Isoleeritud üldisest I. persulcatus'e asustusalast, esinevad tema üksikud kolded vabariigi edelaosa segametsades.

Kõige arvukamat puukide esinemist on täheldatud Eesti NSV lääneosas. Sealsed lepikud, tammikud, sarapikud ja sekundaarsed kuuse-segametsad, 


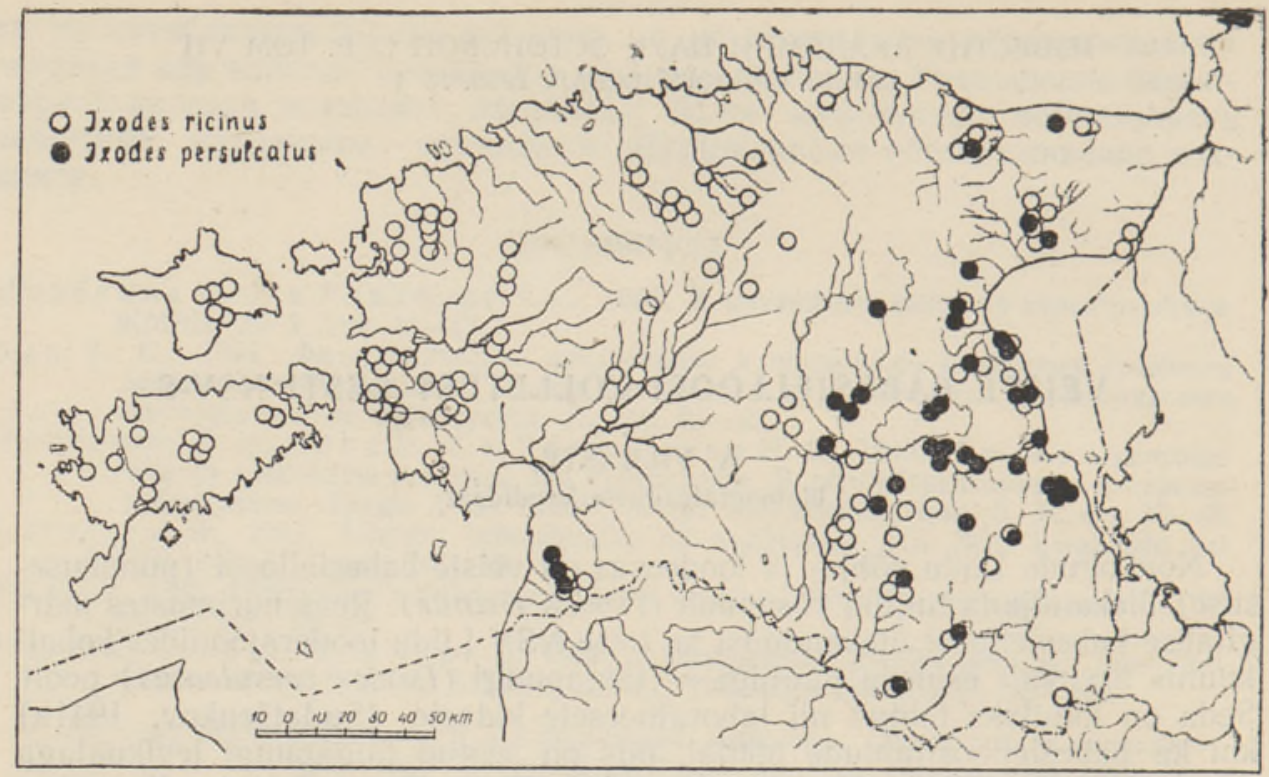

Joon. 1. Ixodes ricinus'e ja Ixodes persulcatus'e esinemine Eesti NSV-s.

mida kasutatakse lühemat või pikemat aega ka veiste karjatamiseks, on peamiseks puukide asumisalaks. Vähemal määral esineb puuke karjamaana kasutatavail puisniitudel. Eriti lepikud on I. ricinus'e massilise paljunemise kolleteks Lääne- ja Loode-Eestis.

Kõrvutades puukide leviku andmeid Eesti NSV Põllumajanduse Ministeeriumi Veterinaaria Valitsuselt saadud andmetega babesielloosi esinemise kohta (joon. 2) selgub, et Lääne-Eestis, kus Ixodes ricinus on ainukeseks puugiliigiks, on ka haigusjuhtude arv kõige suurem (keskmiselt üle 300 aastas). Kuna $I$. persulcatus'e leviku läänepiir jääb babesielloosi massilise esinemise alast tunduvalt ida poole, võib Eesti NSV lääneosas haiguse ülekandjana arvesse tulla vaid $I$. ricinus. Märgatavalt väheneb babesielloosijuhtude arv alles I. ricinus'e ja I. persulcatus'e koosesinemisaladel meie vabariigi kirde- ja edelaosas (25-100 haigusjuhtu aastas), kus mõlemat puugiliiki kohtab enam-vähem võrdselt. Hoopis vähe tuleb babesielloosi ette Eesti NSV kaguosa rajoonides, kus $I$. persulcatus esineb valdavas enamuses või ainukese puugiliigina. Mõnedes Kagu-Eesti rajoonides puuduvad babesielloosijuhud isegi täiesti. Uldiselt esineb Kagu-Eesti liivastel männimetsa-aladel puuke vähe või nad puuduvad täiesti, mis omakorda tingib babesielloosijuhtude vähesuse.

Vaadeldes babesielloosi ajalist esinemist Eesti NSV-s (joon. 3) selgub, et vastavaid juhtumeid on registreeritud meil 8 kuul, maist kuni detsembrini. Massiline haigestumine langeb meie tingimustes juuni- ja juulikuule, mis ühtib ka Tšiž’i (1939) andmetega Karjala ANSV kohta. Samuti täheldati Leedus (Kadyte ja Povilaitis, 1957) suurimat Babesiella'de protsenti veistes juunikuul. Kui nüüd arvestada babesielloosi inkubatsiooniperioodi pikkust ja nimetatud puugiliikide sesoonset dünaamikat (joon. 3), siis tuleks enamik babesielloosijuhte lugeda $I$. ricinus'e poolt ülekantuks. Nimelt kohtab I. ricinus't kogu vegetatsiooniperioodi vältel, kusjuures ta on kõige arvukam mai lõpul ja juuni algul ning augustis ja septembris. I. persulcatus'e aktiivseid isendeid kohtab aga palju lühemas ajavahemikus - mai algusest kuni juuli keskpaigani. Niisiis tuleks I. ricinus'e ja 


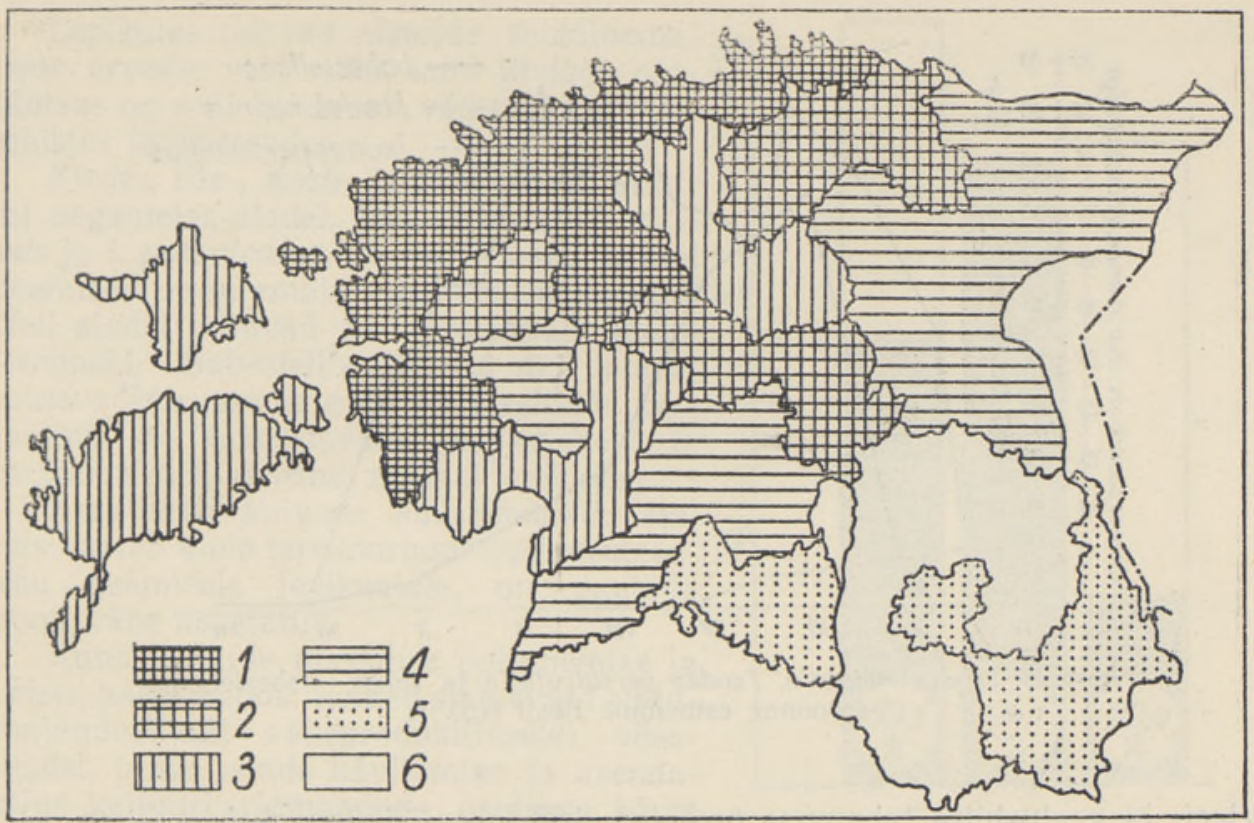

Joon. 2. Veiste babesielloosi esinemine Eesti NSV-s 1951.-1954. a.
1) üle 300 haigusjuhu aastas
2) $200-300$ haigusjuhtu aastas
4) 25-100 haigusjuhtu aastas
3) $100-200$
5) $5-25$
6) alla 5 haigusjuhu aastas

1. persulcatus'e koosesinemisaladel pidada kõik haigusjuhud juuli lõpust alates $I$. ricinus'e poolt ülekantuks. Pealegi on $I$. persulcatus'e esinemissagedus märgatavalt väiksem $I$, ricinus'e omast.

Kuna meil babesielloosi peamiseks ülekandjaks on I. ricinus, püüame lähemalt tutvustada neid tingimusi, mis põhjustavad tema rohket esinemist Eesti NSV lääne- ja loodeosas.

Puugikolded tekivad meil lehtpuude ja põõsaste kasvualal, kus on rikkalikult lehekõdu, mis loob soodsad tingimused puukide arenemiseks, eriti selle elutsükli osa läbimiseks, mille nad veedavad väljaspool peremeest. Mitte vähem oluline puugikollete kujunemise ja püsimise seisukohalt on toitumisfaktor. Selle tõttu ongi puukide asustustihedus suurim neis paikades, kus toimub karjatamine. Pealegi on sellistes kohtades pisiimetajaid rohkesti, mis omalt poolt garanteerib toitumisvõimalused puukide noorstaadiumidele. Karjatatavatel aladel on toitumine tagatud ka täiskasvanud puugistaadiumidele, mistōttu munadest koorunud larvide arv on väga suur, eriti lepikutes. Ainult neis paikades, kus karjatamist suve esimesel poolel ei toimu, näiteks mõnedes laialehistes lehtmetsades, avaneb toitumisvõimalus täiskasvanud puukidele alles sügiskuudel, mil kari lastakse neile aladele. Karjatamise lühiajalisuse tõttu õnnestub toituda üksnes osal emapuukidel. Toitumine metsloomade arvel on inimasulate lähedal minimaalne. Puudujääk täiskasvanud puukide toitumises korvatakse aga suure munaproduktsiooniga (välistingimustes oli $I$. ricinus'e suurimaks munade arvuks ühes kurnas 4246). Neis paikades, kus karjatamine toimub kevadest alates (näiteks lepikutes), leiavad kõik täiskasvanud puugid toitumisvõimalusi.

Hinnates I. ricinus'e peamisi elupaiku Lääne-Eestis tema noorstaadiumis olevate isendite toidubaasi seisukohalt selgub, et kevad-suvisel perioodil, kui pisiimetajate, $I$. ricinus'e larvide tähtsamate peremeeste arv on veel väike 


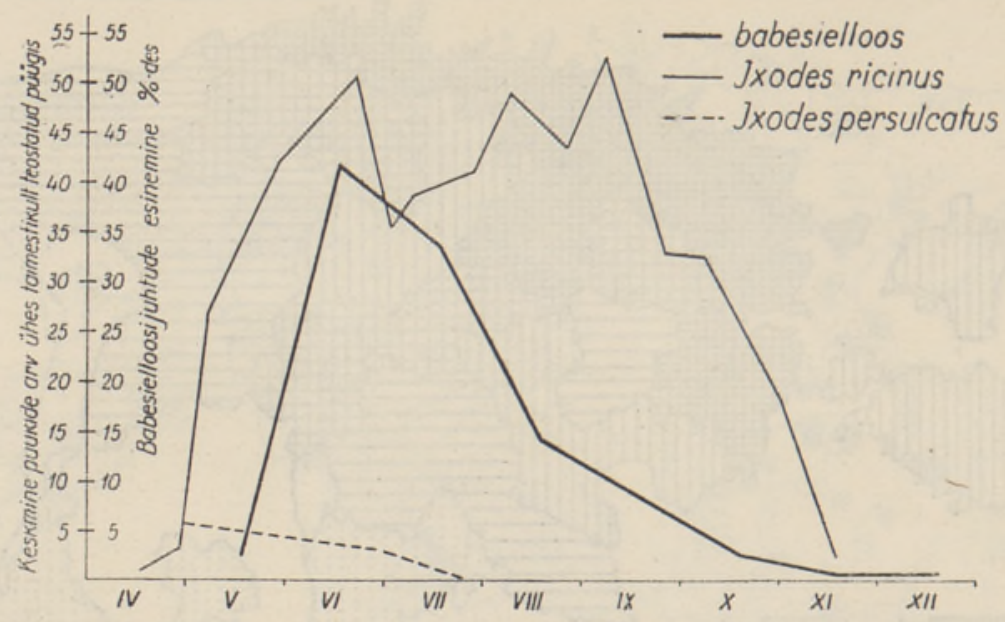

Joon. 3. Ixodes ricinus'e, Ixodes persulcatus'e ja veiste babesielloosi sesoonne esinemine Eesti NSV-s.

(leet- ja kaelushiire tabamuse protsent 100 lõksu-ööpäeva kohta oli 9), ei rahulda lehtmetsades olevad toitumisvõimalused kaugeltki larvide tegelikke vajadusi. Suur osa neist esineb nälginult, sellele vaatamata et nende keskmine $(72,8)$ ja maksimaalne $(403)$ arv ühel pisiimetajal oli kõrge. Alates juulist tõuseb metsahiirlaste arv järsku ja larvide toitumisvõimalused avarduvad mitmekordselt (tabamuse protsent 32), võimaldades enam-vähem kõigil toituda.

Pisiimetajaid esineb sügisel rohkesti ka lepikutes ja puisniitudel (tabamuse protsent kuni 26). Nende nakatamine puukide poolt on aga erinev nende asukoha järgi. Näiteks oli puukidest nakatunud pisiimetajaid lepikutes $94,7 \%$, laialehistes lehtmetsades $59,3 \%$, puisniitudel vaid 30,0\% (joon. 4 ). Samal ajal oli lepikutes (nii taimestikul kui ka pisiimetajatel) larvide arv märgatavalt suurem kui mujal. Sellest võib järeldada, et ka sügisel, hiirte tihedama asustuse puhul ei ole toidubaas lepikutes kõigi larvide vajaduste rahuldamiseks küllaldane. Ja kui täiskasvanud puukidele olid toitumisvõimalused lepikutes veiste karjatamise tõttu eriti soodsad, siis larvistaadiumis ei suuda kõik puukide isendid oma arenemist seal jätkata peremeeste vähesuse tõttu.

Kuna puisniitudel on hiirte fauna küllaldane, millele sügiskuudel lisandub veel karjatamine, siis võiks arvata, et puukide toitumistingimused seal on üldiselt head. Sellele vaatamata on puukide arv puisniitudel väike. Vähesed leiud pärinevad enamasti puude ja põõsaste ümbrusest, kus rohurinne on hõredam, kuid lehekõdu paksem. Uldine puukide vähesus puisniitudel võib olla tingitud mitmesugustest abiootilistest teguritest (otsene päikesekiiritus, madal õhuniiskus, kevadised üleujutused, ebasobivad munemistingimused jne.), mida tõendavad ka Lutta ja Sulmani (1955) vaatlused Karjala ANSV-s.

Nümfistaadiumi jõudnud puukide peremeestena on metsahiirlaste tähtsus tunduvalt väiksem. Samal ajal ilmnes kõrge nakatumisprotsent lindudel. Kuna maas pesitsevaid linde on eriti rohkesti laialehistes lehtmetsades, avanevad nümfidele just seal kõige sobivamad toitumistingimused, mis alates mai lõpust või juunist avarduvad veelgi seoses mitte täiesti lennuvõimeliste noorlindude lahkumisega pesast rohurindesse ja madalamasse võsarindesse, kus nad peamiselt veedavad oma elu kuni sügisese äralennuni. 
Lepikutes tulevad nümfide toiduloomadena arvesse veel siilid, kuid lindude osa- \% tähtsus on seal tunduvalt väiksem kui laialehistes lehtmetsades.

Kirde-, Ida-, Kesk- ja Edela-Eesti suurtel segametsa-aladel, kus esinevad $I$. ricinus ja $I$. persulcatus, on nende levik seotud peamiselt suuremate metsamassiividega. 20 Neil aladel toituvad nad eranditult metsloomadel. Babesielloosikolded neil aladel esinevadki suuremate metsamassiivide karjatamiseks kasutatavatel servamaadel ja metsasihtidel, vähemal määral lepikutes.

Kesk-Eesti kuivade kuusemetsade ala, mis vastab meie territooriumi kultuurmaas. 10 tiku peamisele levikualale, on puukide poolt vähe asustatud.

Kuna puukide massilise paljunemise ja veiste babesielloosi kolded on levinud põllumajanduslikult väheproduktiivsetel võsaaladel, peaks nende hävitamine ja asendamine kultuurkarjamaadega osutuma kõige tõhusamaks võitlusviisiks puukide ja nende poolt ülekantavate haiguste vastu.

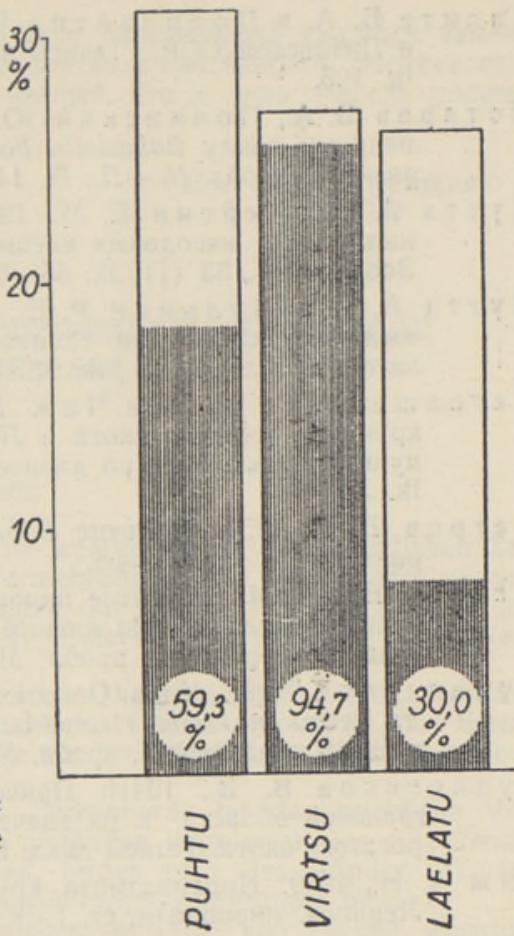

Joon. 4. Pisiimetajate nakatumine Ixodes ricinus'e noorstaadiumidest Puhtu lehtmetsas, Virtsu lepikus ja Laelatu puisniidul 17.-18. IX 1953. (Tulp kujutab pisiimetajate arvu, väljendatud tabamuse \%-des saja lōksu-ööpäeva kohta. Viirutatult - pisiimetajate nakatumine Ixodes ricinus'e noorstaadiumidest \%-des.)

\section{Kokkuvõte}

Babesielloosi massiline esinemine langeb ühte $I$. ricinus'e massilise paljunemise kolletega Eesti NSV lääne- ja loodeosas. Babesielloosi ülekandjaks võib seal olla ainult $I$. ricinus, sest $I$. persulcatus'e leviku läänepiir jääb babesielloosi massilise esinemise alast tunduvalt ida poole.

I. ricinus on levinud peamiselt karjatatavail aladel, eriti karjatatavates lepikutes, tammikutes ja kuuse-segametsades.

Puugikollete püsimise eelduseks on rikkalik pisiimetajate ja maas pesitsevate lindude fauna, kes on toidubaasiks puukide noorstaadiumidele, ning pidev veiste karjatamine, mis loob soodsad toitumistingimused täiskasvanud puukidele. Puude- ja põõsastealune lehekõdu pakub puukidele sobivaid arenemis- ja varjevõimalusi.

Kõige tõhusamaks babesielloosikollete likvideerimise viisiks on vähepro. duktiivsete lepikute ja võsaalade asendamine kultuurkarjamaadega.

\section{KIRJANDUS}

Ф а й н ш тей н $\mathrm{E}$. C., 1939. Микроскопическое исследование мазков пернфернческой крови крупного рогатого скота в пунктах, неблагополучных по бабезнеллозу. Тр. Ленингр. пироплазм. ст. I, lk. 36-39.

Ход ако в ск й А. И., 1939. К экологии пастбищного клеща Ixodes persulcatus применительно к условиям Белозерского района. Тр. Ленингр. пироплазм. ст. 1, lk. 144. 
Кадите Б. А. и По вил айти с В. В., 1957. Бабезиеллоз крупного рогатого скота в Литовской ССР. Тезисы докладов IX совещ. по паразитол. пробл. М.-Л., lk. 105 .

Л о т а е в В.А., Полянский Ю. И. и Хей син Е. М., 1957. Материалы по жизненному циклу Babesiella bovis (Babes). Тезисы докладов. IX совещ. по паразитол, пробл. М.-Л., lk. 143-145.

Л ут т а А. С. и Х ей с и н Е. М., 1954. Некоторые данные относительно роли различных видов иксодовых клещей в распространении бабезиеллоза на Севере. Зоол. журн., 33 (1), lk. 65-68.

Лутта А. С. и Ш ульман Р. Е., 1955. Влияние открытых стаций на активность и выживаемость клеща Ixodes ricinus (L.). Тезисы докл. VIII совещ. по паразитол. пробл. М.-Л., 1k. 91.

Петр ашевская Е. Н. и Ч иж А. Н., 1939. Материалы к изучению бабезиеллоза крупного рогатого скота в Ленинградской области. (Течение пироплазмоза в пунктах различных по давности заболевания.) Тр. Ленингр. пироплазм. ст. I, lk. $3-7$.

Петров В. Г., 1938. Развитие Babesiella bovis в клещах Ixodes ricinus. Сов. ветеринария (3), lk. $51-58$.

П ет ро в В. Г., 1941. Развитие пироплазм Babesiella bovis в клещах Ixodes ricinus L. и метод исследования клещей на вирусоносительство. Тезисы докладов III coвещ. по паразитол. пробл. М.-Л., lk. 29-31.

С уд а ченко в В. В., 1941 а. Опыты по переносу бабезиеллоза крупного рогатого скота клещами Ixodes ricinus L. и Ixodes persulcatus P. Sch. Тезисы докл. III coвещ. по паразитолог. пробл. М.-Л., lk. 25-27.

С уд а ченков В. В., $194 \mathrm{lb}$. Причины мозаичности заклещевания пастбищ Ленинградской области и их значение для эпизоотологии бабезиеллоза крупного рогатого скота. Тезисы докл. III совещ. по паразитол. пробл. М.-Л., $1 \mathrm{k} .41-44$.

Ч и ж А. Н., 1939. Пироплазмоза крупного рогатого скота в Карельской АССР. Тр. Ленингр. пироплазм. ст. 1, lk. 22-30.

Чи ж А. Н., Коновалов А., Кунтышев И., 1951. О течении бабезиеллоза крупного рогатого скота в местностях распространения клеща Ixodes persulcatus. Сб. труд. Ленингр. н-исслед. ветер. ин-та, 4, 1k. 127-132.

Vil b a st e, A., 1953. Uusi puugiliike Eesti NSV faunas. Loodusuurijate Seltsi Juubelikoguteos, 1k. $441-443$.

Eesti NSV Teaduste Akadeemia Zooloogia ja Botaanika Instituut

Saabus toimetusse 16. V 1957

\title{
ОБ УСЛОВИЯХ СУЩЕСТВОВАНИЯ ОЧАГОВ БАБЕЗИЕЛЛОЗА КРУПНОГО РОГАТОГО СКОТА В ЭСТОНСКОИ ССР
}

\author{
А. К. Вильбасте, \\ кандидат бнологических наук
}

Резюме

Область массового распространения бабезиеллоза совпадает с очагами массового размножения $I$. ricinus в западной и северо-западной частях Әстонской ССР. Переносчиком бабезиеллоза в этих местах может быть только I. ricinus, так как западная граница распространения I. persulcatus лежит значительно восточнее массового очага бабезиеллоза.

Распространение I. ricinus в указанных областях связано преимущественно с пастбищами, причем наибольшая чнсленность его отмечена в ольшаниках, дубняках н елово-смешанных лесах, в которых пасется скот.

Существование этих очагов обусловлено богатой фауной мелких млекопитающих и гнездящихся на земле птиц, являющихся кормовой базой для преимагннальных фаз, и постоянной пастьбой скота, создающей благоприятные условня для питания взрослых клещей. Находящаяся под деревьями и кустами лесная подстилка обеспечивает необходиімые условия для развития и укрытия клещей. 
Самым существенным методом ликвидации очагов бабезиеллоза является замена малопродуктивных ольшаников-и кустарников культурными пастбищами. Это повлечет за собой резкое падение численности иксодовых клещей, что в свою очередь должно свести до минимума число случаев бабезиеллоза.

Институт зоологии и ботаники

Академии наук Эстонской ССР
Поступила в редакцию

16 V 1957

\title{
DIE EXISTENZBEDINGUNGEN DER RINDERBABESIELLOSEHERDE IN DER ESTNISCHEN SSR
}

\author{
A. Wilbaste \\ Zusammenfassung
}

Die massenhafte Verbreitung der Babesiellose im westlichen und nordwestlichen Teil der Estnischen SSR ist mit den massenhaften Vermehrungsherden von Ixodes ricinus eng verbunden. Als Uberträger der Babesiellose kommt nur I. ricinus in Betracht, da die Westgrenze der Verbreitung von $I$. persulcatus weit östlicher des Gebietes der massenhaften Verbreitung der Babesiellose verläuft.

Die Verbreitung von I. ricinus ist in jenen Gebieten hauptsächlich mit der Verbreitung der Viehweiden verbunden. Die grösste Anzahl der Individuen wurde in Erlengestrüpp und Eichen-, bzw. Fichtenmischwäldern, die als Weideland benutzt wurden, festgestellt.

Vorbedingung des dauernden Auftretens der Zeckenherde ist das reichliche Vorkommen der Kleinsäugetiere und der am Erdboden nistenden Vogelarten, die eine Ernährungsbasis des Jungstadiums der Zecken darstellen, ferner auch das ständige Weiden der Rinder, die den erwachsenen Zecken günstige Ernährungsbedingungen bieten.

Moderndes Laub unter den Bäumen und Sträuchern gewährt den Zecken günstige Entwicklungs- und Lebensbedingungen.

Die Ersetzung der wenigproduktiven Erlengestrüppe durch hochproduktive Kulturweiden dürfte zur Vernichtung der Zeckenherde wesentlich beitragen. Diese Massnahme könnte eine jähe Verminderung der Zeckenmenge herbeiführen und fernerhin das Auftreten der Babesiellose aufs Minimum herabsetzen.

Institut für Zoologie und Botanik

der Akademie der Wissenschaften der Estnischen SSR
Eingegangen am 16. Mai 1957 